\title{
Type and quality of energy and water in a tropical hospital
}

\author{
Andreas Prasetyadi ${ }^{1,2}$, and Atit Koonsrisuk ${ }^{1, *}$ \\ ${ }^{1}$ Suranaree University of Technology, School of Mechanical Engineering, 30000 Nakhon Ratchasima, Thailand \\ ${ }^{2}$ Sanata Dharma University, Mechanical Engineering Department, 55282 Yogyakarta, Indonesia
}

\begin{abstract}
A hospital is considered an energy gobbler and a water consumer. The energy and water go for many activities in hospital system. HVAC that includes wet cooling tower is the main energy and water consumer in a hospital due to its continuous operation. Conservation of both resources partially depends on the way nexus is managed at the end user. Mapping the energy and water in term of type and quality is proposed as the starting point in managing both as nexus. This article focuses on that part in purpose of integrating energy and water system in a hospital. SUTH, a 120 beds hospital located in tropical area in Thailand that operates daily with $146 \mathrm{~m}^{3}$ water and $1.5 \mathrm{MW}$ of electricity becomes the case of the study. The input and output of energy and water of each subsystem are exposed in addition to subsystems that are described in some different methods. The results show flows of energy and water as by-product that can be used for other systems. Radiology and HVAC release very low enthalpy heat that could not be managed for other utilization, but hemodialysis releases very low heat that is used for its own process. Autoclaves can releases heat that be used for laundry and its own pre-heating. HVAC release brine and distilled water through blow down system and condensation respectively. Electricity is very dominant energy supply of the hospital.
\end{abstract}

\section{Introduction}

Hospital is considered as an energy consumer among large buildings. Hospital energy consumption in Greece was $426 \mathrm{kWh} / \mathrm{m}^{2}$ [1]. In Thailand hospital energy intensity was reported as $243 \mathrm{kWh} / \mathrm{m}^{2}$ [2]. Hospitals in Malaysia consume slightly less than Thailand as 234 $\mathrm{kWh} / \mathrm{m}^{2}$ [3]. Spain hospitals were reported to consume energy annually as much as $270 \mathrm{kWh} / \mathrm{m}^{2}[4]$. The American hospital benchmark for energy consumption is ranging from $160 \mathrm{kWh} / \mathrm{m}^{2}$ until $310 \mathrm{kWh} / \mathrm{m}^{2}$ for small facilities [5] and $437 \mathrm{kWh} / \mathrm{m}^{2}-668 \mathrm{kWh} / \mathrm{m}^{2}$ for large hospital at low energy consumption [6]. Among large buildings, energy consumption intensity of hospital is in the middle of the energy consumption for large buildings [2] and totally hospital represents 6\% energy consumption of building sectors [7]. Most of the energy of the hospital goes for air conditioner that can reaches $51 \%$ [8]. In addition to the HVAC, medical equipment and lighting are the other energy gobbler components of a hospital.

Water is another resource that hospital consumes significantly. According to EPA report, hospital consumes $7 \%$ of total water for commercial and institutional building [9]. The hospital consumes water $144.810^{3}$ gals/bed annually [10]. This number is nearly $20 \%$ above the lodging consumption at the second position among water consumption intensity of large buildings. The water at the hospital, mostly is consumed at sanitary system (42\%) and HVAC (23\%) [11].
Some efforts are reported for conserving water at the hospitals. EPA proposes some activities to conserve water that include maintenance of the system, applying audit of the consumption, retrofitting equipment and application of alternative resources [12]. The maintenance aim is to achieve optimum operation condition. The retrofitting is applied to reduce the consumption through installing new and more efficient equipment. The application of alternative resources is proposed to reduce traditional supply resources share. It increases the supply resilience.

Energy conservation at hospital becomes main topic of some researches. Rehabilitation of envelope is reported reducing energy demand on HVAC by $49.8 \%$ [13]. Optimization of retrofitting CHCP at the 714 beds hospital at Parma was simulated to provide 15 months investment payback period [14]. A 30\% energy saving guidance for small healthcare facilities was reported by Bonnema et al [5]. On the other hand, Buonomano et al. [15] proposed some retrofitting to a hospital that includes rehabilitation of thermal insulation, applying external temperature dependent controllable water valve, installation of thermostatic valve for radiators, and controlling the AHU operation.

Energy efficiency at building can increase water consumption. Energy efficiency at buildings such as hospitals can be achieved through HVAC efficiency which depends on chiller. To work at high efficiency, the chiller should work at low temperature as possible, but keeping the temperature of chiller too low can imply high cost at cooling tower in term of energy and water

$\overline{\text { * Corresponding author: atit@sut.ac.th }}$ 
due to negative approach operation. Over maintenance of the cooling system consumes amount of water that can imply the cost.

Water efficiency at hospital can affect increasing of energy consumption. Some water saving recommended by the guidance of water efficiency such as to reuse water at laundry system, to recycle water system, to utilize blow down water, and to use standardized sanitary equipment have main aim to minimize water withdrawal. Unfortunately, these activities may imply more energy consumption for water processing and pumping or infrastructure. For example, to use recycled water for flushing, it needs different water network and pumping. Additional equipment increases investment, maintenance and operation cost.

Integration is proposed as the way for conserving multi resources system. It is applied at the petrochemical system and many industries for optimizing the energy [16]. At larger scope, total site integration was also proposed to optimize energy consumption at an industrial park and urban $[17,18]$.

Integration is started by mapping the resources which is known as the data extraction. In the data extraction process, resources and its relationship at the facilities are portrayed. At this way, the modules processes are evaluated to understand the resources requirements [19]. The resources requirements are the base of integrating that becomes the main constraint and possibilities of multi resources integration.

This paper is purposed for providing map of energy and water requirements that can be used for integration of energy and water in a tropical hospital with Suranaree University of Technology Hospital (SUTH) as its model. The description of SUTH becomes the second section which is followed by unit operations in modules constructing the SUTH system. This part also provides definition and relationships that is used for describing the system that are sequenced some principle methods. The requirements of energy and water are provided at the forth section followed the discussion of its context. The last section is the conclusion.

\section{Suranaree University of Technology Hospital (SUTH)}

SUTH is a 120-bed hospital and it has 558 staff. It is affiliated with the Institute of Medicine of Suranaree University of Technology. The operational hospital consists of 6 buildings. There are main building, imaging (radiology) building, health promotion building, service building, and dormitory. The main building is the largest building as indicated in the circle in Fig. 1. It is an 11story building with total area $19,000 \mathrm{~m}^{2}$. The out-patient division, operations, and wards are located in the main building. The radiology building is provided for imaging equipment such as X-Rays, MRI and CT Scan. The health promotion building is former hospital that is functioned as outpatient clinic at over time and conference. The service buildings composed of building for sterilization and laundry, and food preparation building.
Total electricity and water consumptions of SUTH at August 2017 are $9100 \mathrm{kWh} /$ day and $146 \mathrm{~m}^{3} /$ day, respectively. The main building consumes approximately $69.3 \%$ and $63.6 \%$ of the respective total electricity and water consumption. Building for sterilization and laundry consumes $15.3 \%$ of electricity. The radiology building electricity consumption is $11.4 \%$ of total electricity consumption. The food preparation building shares nearly $2.8 \%$ of electricity need. The waters consumption of laundry and sterilization building, and food preparation building are $33.4 \%$, and $2 \%$ respectively. The radiology building only consumes minute water, less than $1 \%$.

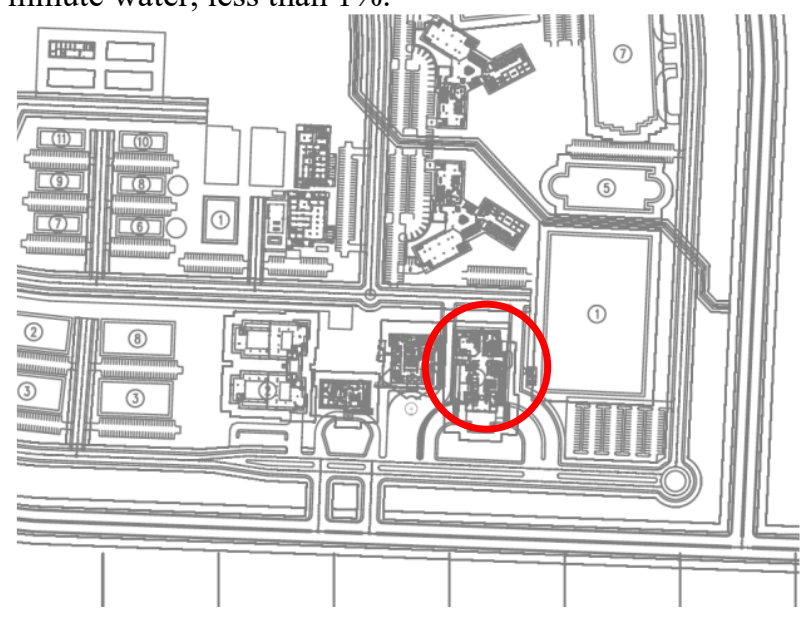

Fig. 1. Top view of SUTH. Main building is circled in the figure.

The HVAC systems for the buildings are built independently. Every building has its own HVAC system. The main building, and the sterilization and laundry building have centralized HVAC with cooling capacity $8,000,000 \mathrm{btu} / \mathrm{hr}$ and $3,208,000 \mathrm{btu} / \mathrm{hr}$, respectively. The main building applies water chiller system and has wet cooling tower as its heat rejection equipment. The sterilization building has dry cooling system. The other buildings apply split system for the HVAC with cooling capacity around 1 million btu/hr for each building.

At the basement of main building, there are 3 chillers and each chiller has a capacity of $250 \mathrm{TR}$ with a chiller water flow rate of $70.80 \mathrm{~m}^{3} / \mathrm{hr}$. The designed temperature of the chilled water is $7-13.5^{\circ} \mathrm{C}$. The chillers are supported by 3 chilled water pumps for distributing the chilled water. There are 3 water pumps that transfer condenser water from the chillers to cooling tower at rooftop.

The HVAC system of the main building rejects heat to the atmosphere through 3 mechanical-draft cooling towers. Each cooling tower has a capacity of 953,904 $\mathrm{kcal} / \mathrm{hr}$ or $3.8 \mathrm{million} \mathrm{btu} / \mathrm{hr}$. It has water flow rate 750 gpm. The air flow rate of a cooling tower is $1850 \mathrm{~m}^{3} / \mathrm{min}$ with fan speed $350 \mathrm{rpm}$. A motor for fan of the cooling tower is $10 \mathrm{HP}$.

Water used in SUTH is supplied by the tap water system of Suranaree University of Technology (SUT). The tap water is first stored in a $130 \mathrm{~m}^{3}$ underground storage in the main building, and then sent to a $50 \mathrm{~m}^{3}$ 
water tower on the rooftop on the building using 2 pumps. Each pump has a capacity of $50 \mathrm{~m}^{3} / \mathrm{hr}$ and a head of $85 \mathrm{~m}$.

SUTH has a package water treatment plant with a capacity of $220 \mathrm{~m}^{3} /$ day. To treat the wastewater, the plant uses an activated sludge process with a system of continuous and sequential aeration ponds. Currently the plant treats only wastewater from the main building. The treatment level is secondary which can produce water with the BOD (biological oxygen demand) level of 20 ppm.

The electricity system of the hospital is connected to the grid through $2 \times 1,250-\mathrm{kW}$ transformers. There is a backup power system with a $1100-\mathrm{kVA}$ generator and a $220 \mathrm{~kW}$ generator for data center. Additionally, there is an emergency power system for the operation rooms, with 30 minutes of backup time.

\section{Modules and the operation units}

The following section consists of two parts, they are the definition, and the systems of energy and water descriptions. The first part discusses about some terms that connect integration term and the common term of modelling. The second part describes the work of the systems and their requirements.

Some methods are applied to describe the modules. They are input-output of mass flows, table of inputoutput, block diagram, black box and activity diagram. The input-output of mass flows diagram only describes the material flowing at the modules. Input-output table mentions the energy and water input and output at every modules of the system. Black box diagram describes the activity of a system as hidden process that provides energy and material input and output. The block diagram depicts a module, its energy and water input-output at diagram format instead of table. Activity diagram is used to portray in relative detail activities taking places at the module.

Structural diagram is applied to describe relation among the term concepts. Relations of system, modules, unit operation are provided in a block diagram. Hierarchical relation is the basic principle of this structural diagram.

\subsection{Definition}

Module at the term of integration is functional steps that consist of operation units. A module can have some steps of specific function and may represent sequence activities. For example, a chiller module consists of evaporation unit, compressing unit, condensing unit and expansion unit. If a module consists of single operation unit, it is also an operation unit. This definition of a module implies that a system is composed of some modules. The relation of a system, modules and operation units is mentioned in Fig. 2. It also shows that they have structural relationships.

A facility at a hospital consists of modules that form a system. Every system has some activities that can occur serially or in parallel. HVAC system consists of
AHU/FCU modules, chiller module, cooling tower and soften water module. These modules operate together in parallel and sequential ways to fit the function of a HVAC system.

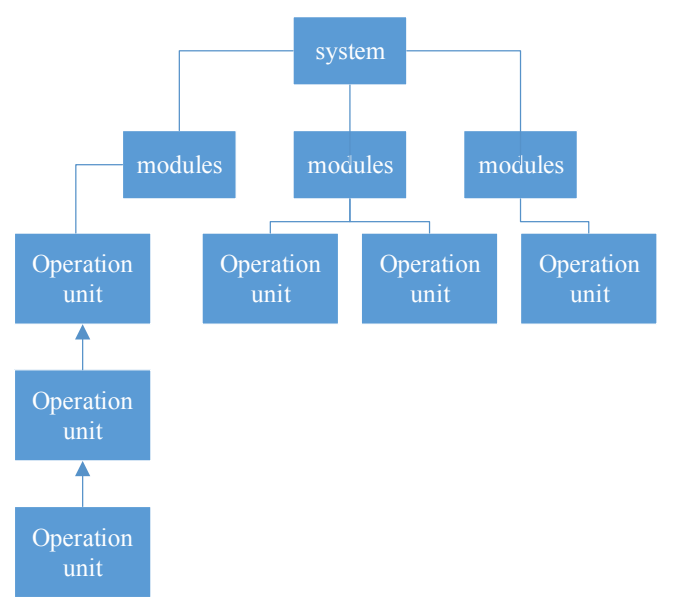

Fig. 2. Structural relation of system, modules and operation units

The definition of hospital facility does not mean medical function, but it refers to technical or equipment facility, such as HVAC system, sanitary system, and sterilization system rather than out-patient clinic, wards and offices. Therefore the hospital facility is considered as technical functional equipment systems. The activities of hospital are represented by some functions of equipment. This equipment can be a module such as AHU, FCU, and chiller. The other equipment could be an operation unit such as pump and water heater.

\subsection{SUTH systems and modules}

The systems of SUTH that will be discussed at this paper are HVAC, sanitary system, autoclaves system, laboratory system, radiology system, and hemodialysis system. The choice is based on energy consumption and water consumption of the system. Lighting, even usually it consumes $12 \%$ of energy consumption [20], is out discussed because it is not connected directly to water.

The discussion of every module is focused on inputoutput energy and water. Input energy represents the energy for the module operating. Output energy represents every types of energy released by the operating module. Similar principles are also applied to the water of modules. Input-output energy and water are categorized to be existing and probable. The output includes by-product of operation.

\subsubsection{HVAC}

The HVAC system consists of AHU and FCU, chiller, cooling tower and soften water system. All of the modules apply electricity as the energy source. Therefore, the only input energy is electricity. But some modules produce by-product energy (heat) and byproduct mass that is type of water. 
At the chiller module, there are two main mass flows in addition to refrigerant. They are chilled water flows and condenser flows. The chilled water flows connect the chiller and the FCU/AHU or refrigerator. The condenser water connects chiller to the cooling tower. The chiller transfers heat from chilled water to condenser water. The chilled water flow is closed system without significant water alteration. The condenser water has alteration due to evaporation at the cooling tower which increases the conductivity and reduces the volume of condenser water. To compensate the volume and conductivity, additional soften water should be added as make-up water. This additional make-up water volume depends on the cycle design. Therefore the quality of chilled water is relatively constant, but the quality of condenser water is ranging from $75-225 \mu \mathrm{S} / \mathrm{cm}$.

The AHU and FCU have two main flows, they are air flows and chilled water flows. Both modules need electricity as the energy input and can be considered not producing by-product energy. The AHU mostly produces condensed water as by-product because it has additional outdoor air that has higher temperature and relative humidity than room temperature and humidity. The process at AHU consists of temperature cooling and dehumidifying. On the other hand FCU does not produce water as by-product due to small change of humidity because the air flow is relatively closed.

Volume of distilled water as by-product of psychrometric process at AHU depends on air change and the different temperature and humidity between the outdoor air and room air. The more air change rate is the more by-product water can be produced while the outdoor air is more humid.

The cooling tower needs electricity to operate and release heat to the atmosphere through evaporation principle. It has water input that is condenser water coming from the chiller. It returns the condenser water with alterations, they are conductivity increase and volume decrease. The volume alteration is compensated by make-up water, but the conductivity alteration should be compensated through blow-down water.

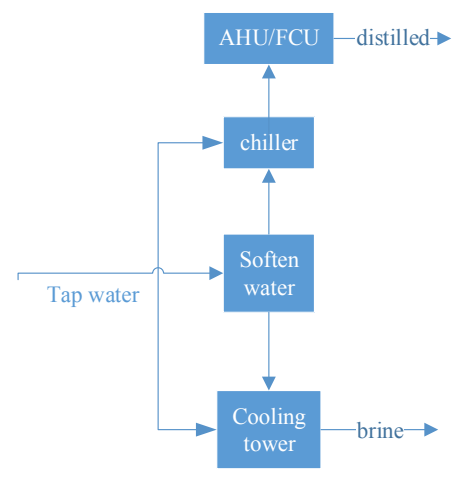

Fig. 3. Input and output mass flow of HVAC modules

The blow-down water is released as brine water from the cooling tower to environment. To keep the cooling tower operate optimally, the blow-down water should be released when the conductivity reaches $225 \mu \mathrm{S} / \mathrm{cm}$ or the water is categorized as slightly hard. Additional equal volume soften water is made after the water blew down.
Through this method, the condensate water for cooling tower and chiller is kept at operation range.

\subsubsection{Sanitary}

The main function of sanitary system is to provide water for domestic daily use, such as toileting, showering, teeth brushing, and hand washing for the patient, staffs and attendances. Input-output of energy and water at the sanitary system is provided in Table 1 . Most of the water is going for flushing and hand washing due to people activities. Hot water system also important at this point, even it is shown as different module.

To provide the sanitary system, pumps are applied for moving the water from ground water storage to rooftop storage. Booster pumps are also prepared for the last 4 stories. Some valves are applied to control the flow of the water, therefore the faucets can flow water at $1.5-$ 3.5 gallons/min.

Hot water is provided by the electric heater in every place that needs it. The reasons of safety base this choice. Hot water network becomes problems in a hospital due to scalding and legionella problems. Managing hot water to keep at safe temperature can imply the legionella bacteria proliferation.

This simple sanitary system has input energy of tap water and output waste water. Electricity is the only energy input. The temperature of water input is $27^{\circ} \mathrm{C}$ in average, which is less then legionella proliferation window.

Flushing can be done by less quality of water. It can use recycle water with level 2 treatment criteria. The water should be clean, odourless and free of pathogen bacteria.

Table 1. Energy and water input-output of sanitary modules

\begin{tabular}{|c|c|c|}
\hline Modules & Input & Output \\
\hline $\begin{array}{c}\text { showering, teeth } \\
\text { brushing, hand } \\
\text { washing }\end{array}$ & $\begin{array}{c}\text { electricity } \\
\text { tap water }\end{array}$ & waste water \\
\hline hot water & $\begin{array}{c}\text { electricity } \\
\text { heat } \\
\text { tap water }\end{array}$ & waste water \\
\hline flushing & $\begin{array}{c}\text { electricity } \\
\text { tap water } \\
\text { recycled water }\end{array}$ & waste water \\
\hline
\end{tabular}

\subsubsection{Radiology}

The radiology system of SUTH consists of x-rays, MRI, CT-scan equipment and their support systems which are located at radiology building. This 2 -story building is dedicated for radiology equipment and does not have any ward for patient. Some conferences and offices are provided. Therefore, the radiology equipment only consumes energy for running the equipment and cooling system. The water is consumed for sanitary which is very few due to its operation time and low occupancy area.

Cooling system for the building is provided by split HVAC system and one single dry cooling condenser for 
removing heat from MRI. The split cooling system provides 1 million cooling capacity totally. The condensers of the equipment are located inside of the building with air cooling system. At that room, additional cooling apparatus is prepared to remove heat released by condenser. Higher cooling capacity is applied for condenser room.

The only energy supplying the system is electricity. It does not produce energy by-product. Because it only has split system, HVAC of the building does not produce any by-product mass. The heat released from the equipment is directly surpassed by the HVAC.

The radiology system at SUTH is already digitalized, the results are provided in digital format and sent by network. It implies that the system does not need any water for image processing. But it needs additional electricity to run data-centre and its cooling.

\subsubsection{Hemodialysis and laboratory system}

The hemodialysis modules and laboratory represent similar requirement. The modules consume electricity energy for running the equipment. Both system also consume some water requirement. They need ultrapurified water. Therefore both modules need ultrapurification water treatment by RO system. A block diagram of hemodialysis system equipment is mentioned in Fig. 4. The system has RO system apparatus and hemodialysis instrument. In addition to the ultra-purified water, both also need tap water for cleaning some equipment.

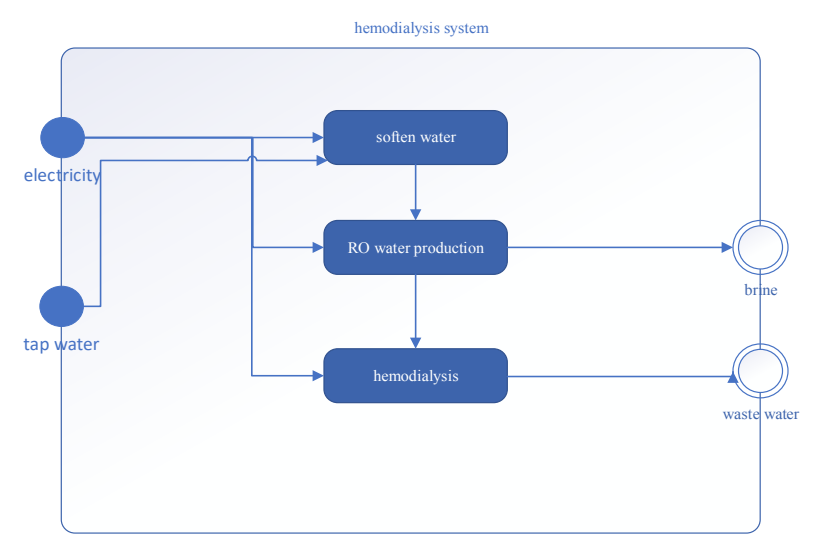

Fig. 4. Block diagram of hemodialysis apparatus

The energy for equipment of the modules is electricity. Electricity is applied for hemodialysis and RO water system. The equipment produces a few heat that is not collected due to economical consideration. Sensitive water heater is applied during the process of hemodialysis especially to heat the RO water to be equal to patient body temperature. Some heat is also produced by the equipment that currently is removed by the HVAC. The black box of the hemodialysis module is provided in Fig. 5.

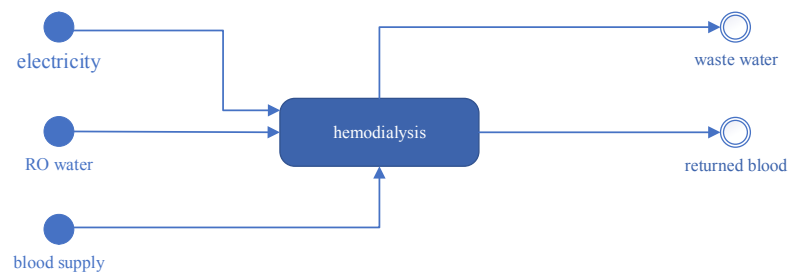

Fig. 5. Black box of hemodialysis module that describes its activity

\subsubsection{Autoclaves and sterilization}

The autoclaves are prepared to provide steam at the sterilization and laundry. It has operation temperature range of $140-165^{\circ} \mathrm{C}$. The total capacity of a boiler is 11.7 million btu/hr. The fuel consumption of the system is 350 litres/day. The system also applies electricity for pumping the water to the boiler and returning the used steam to the boiler.

The autoclaves have soften water input with conductivity of $75 \mu \mathrm{S} / \mathrm{cm}$. The soften water is supplied the boiler as make up water, while some of steam is released due to leakage and blow down. It implies that the autoclaves need soften water as its mass input. It also releases hot brine which is considered as useful hot water in term of energy.

Some of the steam from the autoclaves is reused for laundry system after it is used for sterilization. This steam is used for ironing, drying and providing hot water. The steam flows from autoclaves to sterilization equipment. Some of the steam is condensed due to the temperature, but some of the steam still has high temperature to dry the laundry, to iron and produce hot water for washing and pre-treatment at sterilization unit.

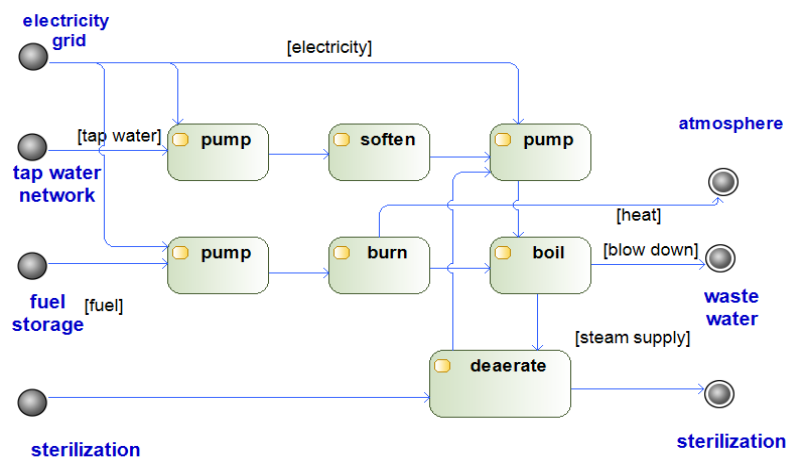

Fig. 6. Activity diagram of autoclave

Therefore the autoclaves consume electricity and fuel as its energy input. It also produces energy by-product and water by-product. The energy by-product is the form of heat. The water by-product is the form of blow-down that should be treated. The complete activity of autoclave is presented in Fig. 6 . 
Table 2. Water input and by-product of system.

\begin{tabular}{|c|c|c|c|c|c|c|c|c|}
\hline \multirow{2}{*}{$\begin{array}{c}\text { System } \\
\text { (modules) }\end{array}$} & \multicolumn{5}{|c|}{ Consumption } & \multicolumn{3}{|c|}{ Released Water } \\
\hline & $\begin{array}{c}\text { Tap } \\
\text { Water }\end{array}$ & $\begin{array}{c}\text { Hot } \\
\text { Water }\end{array}$ & $\begin{array}{c}\text { RO } \\
\text { Water }\end{array}$ & $\begin{array}{l}\text { Soften } \\
\text { Water }\end{array}$ & $\begin{array}{l}\text { Recylced } \\
\text { water }\end{array}$ & $\begin{array}{l}\text { Waste } \\
\text { water }\end{array}$ & Brine & $\begin{array}{c}\text { Distilled } \\
\text { Water }\end{array}$ \\
\hline HVAC & $\sqrt{ }$ & & & $\sqrt{ }$ & & & $\sqrt{ }$ & $\sqrt{ }$ \\
\hline Laboratory & $\sqrt{ }$ & $\sqrt{ }$ & $\sqrt{ }$ & & & $\sqrt{ }$ & & \\
\hline Flushing & $\sqrt{ }$ & & & & $\sqrt{ }$ & $\sqrt{ }$ & & \\
\hline $\begin{array}{l}\text { Showering and } \\
\text { teeth brushing }\end{array}$ & $\sqrt{ }$ & $\sqrt{ }$ & & & & $\sqrt{ }$ & & \\
\hline Autoclaves & & & & $\sqrt{ }$ & & & $\sqrt{ }$ & \\
\hline Laundry & $\sqrt{ }$ & $\sqrt{ }$ & & & $\sqrt{ }$ & $\sqrt{ }$ & & \\
\hline Food Preparation & $\sqrt{ }$ & $\sqrt{ }$ & $\sqrt{ }$ & & & $\sqrt{ }$ & & \\
\hline Drinking & & & $\sqrt{ }$ & & & & & \\
\hline Hemodialysis & $\sqrt{ }$ & & $\sqrt{ }$ & & & $\sqrt{ }$ & & \\
\hline Dish washing & $\sqrt{ }$ & $\sqrt{ }$ & & & & $\sqrt{ }$ & & \\
\hline $\begin{array}{c}\text { Outdoor } \\
\text { irrigation }\end{array}$ & & & & & $\sqrt{ }$ & & & \\
\hline Fire Supression & $\sqrt{ }$ & & & & & & & \\
\hline
\end{tabular}

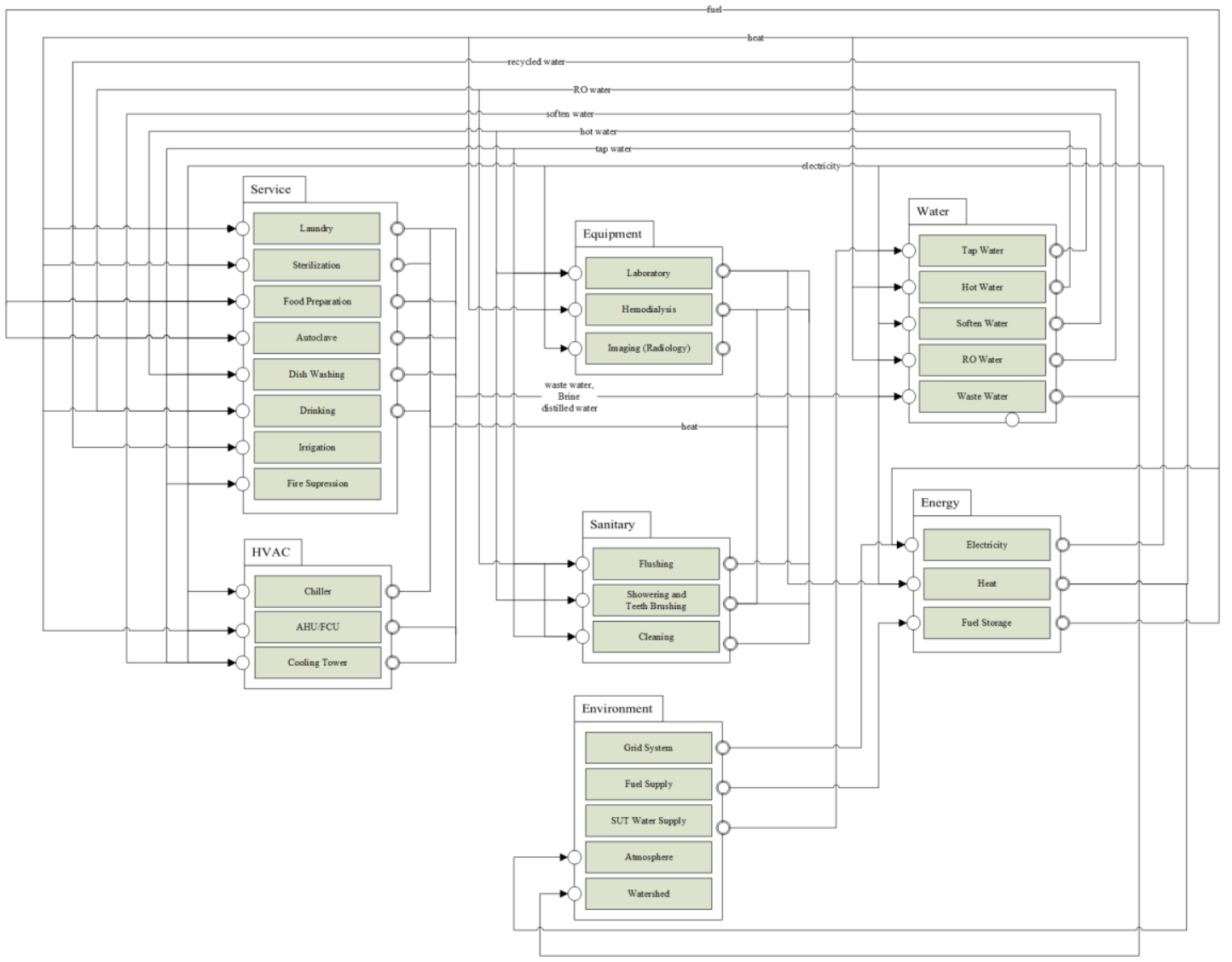

Fig. 7. Energy and water flows at the hospital

\section{Discussion}

Energy and water flows at SUTH are mentioned in Fig. 7. It shows map of energy and water at the hospital. The figure mentions Soften Water, RO Water, and hot Water as single modules even they are practically distributed at several modules. The aggregation is also applied for the AHU/FCU. The detail of the flows can be referred to the block diagram or activity diagram of the module as mentioned in Fig. 4. and Fig. 6.

Map of water of the SUTH is provided in Table 2. In this table, the probable water that can be used for every system is shown as well as the water that can be collected at the system or module. These probable 
resources are added as the addition to the existing condition. For example, a cooling tower can use also tap water as its make-up water as long as the tap water is soft enough. Harder water for cooling tower increases the deposition of salt on the surfaces. This crust decreases the cooling tower performance.

If the tap water with higher conductivity is chosen for make-up water, the water cycle of the system will be very low. For example soft water with $100 \mu \mathrm{S} / \mathrm{cm}$ is used for the make-up water and the cooling tower evaporates $10 \%$ of water, the cycle of water is 10 if the limit is 200 $\mu \mathrm{S} / \mathrm{cm}$. If $150 \mu \mathrm{S} / \mathrm{cm}$ water is used, the cycle is 7 . It means that the cooling tower with $150 \mu \mathrm{S} / \mathrm{cm}$ should blow-down when the cooling tower has already added make-up water 7 times. Less cycle water means more water that is consumed and more brine released.

Table 2 also mentions that some activities can use partially or totally recycled water. Irrigation can apply totally recycled water. But laundry only use partially recycled water for the reason of hygienist. The recycled water can be managed for pre-treatment of laundry system. Flushing can use recycled water totally, but differing flushing water network and showering water network implies more investment.

Heat is released at autoclaves as by-product through steam, blow down and burning process. It can be used at the laundry system for pre-treatment or producing hot water. The steam can be used for ironing, drying and producing hot water through heat exchanger. Blow-down water can be used for increasing the low temperature hot water. This process should consider about the legionella proliferation [21]. Pinch processes in detail should be regarded.

Some system released heat, but in very low enthalpy. Radiology, HVAC, hemodialysis systems are the systems that release heat which is not economical for other system utilization. Table 3 shows the heat released by system or module and its necessity.

In Table 3, it is shown that HVAC can release very low temperature heat, but need at least low heat. It implies that HVAC never uses its own heat for reducing energy for heating that is used at HVAC. For the tropical area, where the HVAC is focused on cooling, heat can be used for absorption cooling system or dehumidifying system.

Laboratory and hemodialysis modules have different character of heat. Laboratory releases very low heat but need at least low temperature heat. This low temperature is used for some cleaning activity or for heat exchanging processes. Hemodialysis module needs only very low heat for increasing the temperature of RO water for dialysis process. The RO water has to have equal temperature to the blood.

Sanitary system only releases very low temperature heat and need low or medium. It needs temperature above $70^{\circ} \mathrm{C}$ that makes sure the safety of the product. At temperature above $70^{\circ} \mathrm{C}$, the legionella bacteria do not exist. Having the temperature below $70^{\circ} \mathrm{C}$, it increases risk of legionella proliferation at the equipment.

The autoclave can release heat that is higher than heat necessity temperature for economizing its own process and other processes. Very low temperature heat is useful to increase the pre-treatment process. The legionella is not considered in this process, while the total provides temperature far above the legionella windows. The autoclave also releases heat with temperature that can be transferred to other modules. To utilize this potentiality, consideration of quantity should be taken into account.

Food preparation needs low or medium heat for reducing heating process in addition to autoclave and sterilization. Consideration of such temperature is based on the pathogen germ that should be limited at the processes or related process. Such temperature is used for pre-treating food or first dish washing.

The sterilization can use its own released heat for its own processes. Cleaning equipment before sterilization can utilize waste heat of sterilization machine. The process can fasten condensation. But this procedure can imply additional pump and deaerator for the condensed water.

Table 3. Heat necessity and released by system or module. VL: very low $\mathrm{T}<40^{\circ} \mathrm{C}, \mathrm{L}$ : low $\mathrm{T}<90^{\circ} \mathrm{C}$, M: medium $\mathrm{T}<140^{\circ} \mathrm{C}, \mathrm{H}$ : high $\mathrm{T}>140^{\circ} \mathrm{C}$

\begin{tabular}{|c|c|c|}
\hline System / Module & Heat Release & Heat Necessity \\
\hline HVAC & VL & L, M, H \\
\hline laboratory & VL & L \\
\hline hemodialysis & VL & VL \\
\hline sanitary & VL & M, H \\
\hline autoclave & L, M & VL, M, H \\
\hline laundry & VL, L & M, H \\
\hline food preparation & L, M & VL, L \\
\hline drinking & VL & VL, L, M \\
\hline sterilization & L, M & L, M, H \\
\hline
\end{tabular}

\section{Conclusion}

The hospital utilizes tap water, hot water, RO water, soften water and recycled water for processes, and releases waste water, brine and distilled water. Some released by-product can be used for other system. The recycled water can be used for irrigation, laundry, and flushing. HVAC also produces distilled water through psychrometric process at AHU. HVAC and hemodialysis release brine that can be recycled without a lot of treatment.

Electricity is main energy that is applied at all of the systems. Some of the system can use low quality of energy, such as heat. Laundry system uses waste heat released by autoclaves. Consideration of hot water production should be applied for preventing legionella proliferation.

Heat is energy that can be used for reducing primary energy consumption. Some system or modules can reuse its own released heat in term of quality. Some other system or modules are impossible to utilize its own waste heat. In addition to the quality of energy, quantity has to be calculated in detail for the future work.

The authors would like to express gratitude to SUT for providing the Postgraduate Scholarships for Foreign Students to the first author. The authors also would like to express their 
sincere thanks to the SUTH director Dr. Likit Matrakul, and the Engineering and Maintenance Department staffs of SUTH, particularly to Mr. Watcharin Singtana, Mr. Songkrit Jitpakdeebordin, Mr Chaleomkiat Kaewkurn, Mr. Prashya Suranachit, and Ms. Porntip Prapin. Expression of gratitude for Yayasan Sanata Dharma for support of fund for the $1^{\text {st }}$ author is declared.

\section{References}

1. H. Sayyaadi, M. Nejatolahi, Int. J. Refrig. 34, 14 (2011)

2. EPPO, Thailand 20-Year Energy Efficiency Development Plan (2011 -2030) (2016)

3. R. Saidur, M. Hasanuzzaman, S. Yogeswaran, H. A. Mohammed, M. S. Hossain, Energy 35, 6(2010)

4. A. G. González, J. García-Sanz-Calcedo, D. R. Salgado, Sustain. Cities Soc. 36, 7(2018)

5. E. Bonnema, S. Pless, I. Doebber, J. Healthc. Eng. 1, 20(2010)

6. E. Bonnema, D. Studer, A. Parker, S. Pless, P. Torcellini, Large Hospital $50 \%$ Energy Savings: Technical Support Document Large Hospital $50 \%$ Energy Savings: Technical Support Document ,(2010)

7. A. Teke, O. Timur, Renew. Sustain. Energy Rev. 33, 12(2014)

8. N. Thinate, W. Wongsapai, D. Damrongsak, Energy Procedia 141, 5(2017)

9. U.S. Epa, Saving Water in Hospitals (2012)

10. Commercial Buildings Energy Consumption Survey: Consumption and Expenditures Tables (2012) [Online]. Available: https://www.eia.gov/ consumption/commercial/reports/2007/xls. [Accessed: 20-Feb-2018]

11. Hospital Energy Alliance, Hospitals Save Costs With Water Efficiency, (2011)

12. Office of Water U.S. Environmental Protection Agency, WaterSense at Work: Best Management Practices for Commercial and Institutional Facilities (2012)

13. F. Ascione, N. Bianco, R. Francesca, D. Masi, G. Peter, Energy Build. 60, 14(2013)

14. G. Pagliarini, C. Corradi, S. Rainieri, Appl. Therm. Eng. 44, 9(2012)

15. A. Buonomano, F. Calise, G. Ferruzzi, A. Palombo, Energy, 78, 18(2014)

16. T. Gundersen, Heat integration: targets and heat exchanger network design, 61 (2013)

17. P. Yen et al., Renew. Sust. Energy Rev. 68, 22(2017)

18. R. J. Hassiba, P. Linke, Appl. Therm. Eng. 127, 14(2017)

19. M. Yang, X. Feng, G. Liu, Appl. Energy 162, 10(2016)

20. N. Christiansen, M. Kaltschmitt, F. Dzukowski, Energy Build. 131, 12(2016)
21. I. Marchesi, P. Marchegiano, A. Bargellini, S. Cencetti, G. Frezza, M. Miselli, P. Borella, J. Hosp. Infect. 77, 5(2011) 